\title{
Government launches campaign to cut alcohol related deaths
}

"Our data indicate a moderately increased risk of congenital malformations associated with prenatal exposure to SSRIs," write the authors, from Aarhus University Hospital in Denmark. "Further studies are needed to confirm this risk and to clarify whether the risk is attributable to the drugs themselves, to underlying psychiatric disease, or to other confounding factors."

Roger Dobson Abergavenny

\section{New gonorrhoea strains are resistant to antibiotics}

The number of strains of gonorrhoea that are resistant to antibiotics has continued to increase in England and Wales, despite recommended changes to first line treatment. Gonorrhoea is the second most commonly transmitted bacterial sexual infection in the United Kingdom.

Figures released by the Health Protection Agency last week indicate considerable regional variations in levels of resistance and sharp increases in resistance among gay men and men who had sexual contact while abroad.

The report was based on results of tests on more than 1600 isolates - mostly from specimens from genitourinary medicine clinics-collected over three months in 2005 in England and Wales as part of the agency's annual surveillance programme.

More than one in five isolates (22\%) were resistant to the fluoroquinolone ciprofloxacin, up from $14 \%$ in 2004 . In all regions at least $10 \%$ of isolates were resistant to ciprofloxacin, but the percentage was highest in the south east of England at 42\%.

Resistance to penicillin also rose, from $11 \%$ of isolates in 2004 to $18 \%$ in 2005 , but ranged from zero in the east of England to $25 \%$ in London. Much smaller rises were reported for tetracycline (4\%) and azithromycin $(0.4 \%)$.

Caroline White London

GRASP, The Gonococcal Resistance to Antimicrobials Surveillance Programme: Annual Report, 2005 is available at www.hpa.org.uk.

\section{South Africa acts to curb spread of lethal strain of $\mathrm{TB}$}

The South African government has invited experts from the World Health Organization to meet next week in a bid to formulate a plan to combat the rise in multidrug resistant and extensively multidrug resistant tuberculosis.

The move comes amid allegations that the government has failed to act promptly.

South Africa's Medical Research Council, its National Health Department, and WHO say that none of the drugs currently available in South Africa for first or second line treatment of tuberculosis is effective against the extensively resistant variant.

The government's response follows an emergency meeting held last month in Johannesburg that was attended by representatives from the Medical Research Council, WHO, and the US Centers for Disease Control but not health department officials

About $500000 \quad$ South Africans have tuberculosis, most of whom are also infected with HIV. Around 6000 people have the multidrug resistant variant.

The extensively resistant variant first came to public attention when it was diagnosed in some 50 people in a rural hospital in KwaZulu-Natal.

They were all HIV positive and died rapidly. All but one had died when a paper dealing with the phenomenon was presented at this year's international AIDS conference in Toronto. Most provinces around South Africa have now reported cases of the deadly variant.

It has since become clear that the problem has been around for longer than health department officials have suggested, although as the $B M J$ went to press South African government officials had not responded to requests for a comment on the apparent delay.

Pat Sidley Johannesburg
Government ministers are launching a high profile advertising campaign in England to try to reduce the amount of injury and death among young people caused by binge drinking.

The $£ 4 \mathrm{~m}(€ 6 \mathrm{~m} ; \$ 7.4 \mathrm{~m})$ initiative, run jointly by the Department of Health and the Home Office, will target 18 to 24 year olds who drink heavily. Department figures show that $48 \%$ of men and 39\% of women in this age group drink over the limit of what is considered safe.

The public health minister, Caroline Flint, said: "In England it is estimated that 5.9 million people drink to get drunk. Males and females aged 18 to 24 are our priority in this campaign, as they are the most likely to drink irresponsibly.

"The 'Know Your Limits' campaign will support the actions that the government is taking to tackle the problem of alcohol related harm, and we hope it will help create a culture where drinking responsibly is the norm.'

The advertisements have also been designed to appeal to a slightly younger age group, as research indicates that illegal drinking, including binge drinking, is also increasing in this age group.

Ian Gilmore, president of the Royal College of Physicians, said: "This launch is really important. If we can start to change young people's drinking patterns, there is a chance that we may begin to turn the tide of

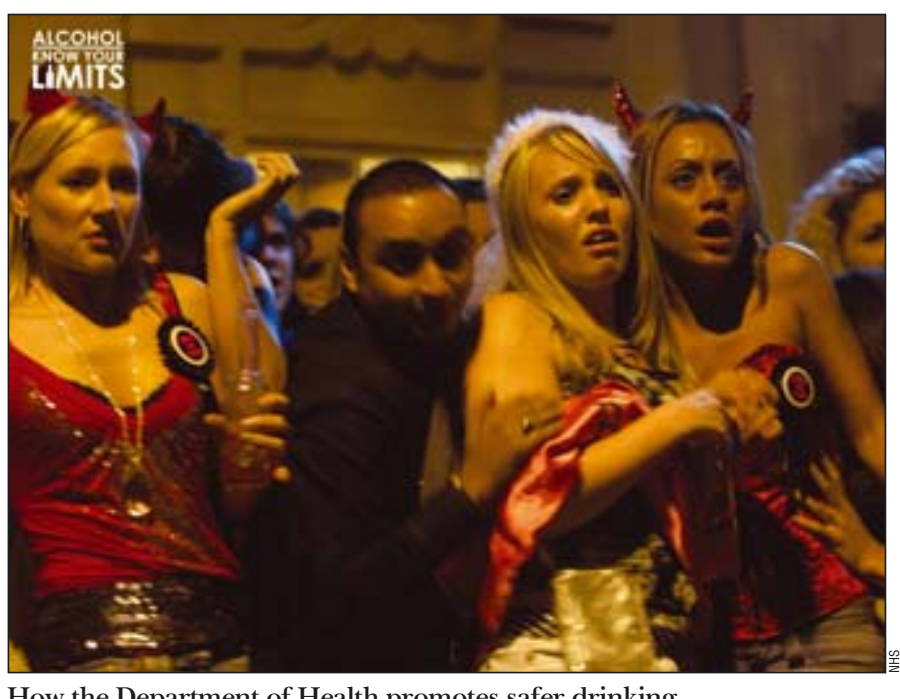

escalating cirrhosis deaths that we are currently seeing in people in their 30 s and 40s."

The campaign will start on television on 16 October and will then be rolled out across cinemas, radio, magazines, and online throughout November. It will illustrate what can happen when drunk youngsters fall from high scaffolding, stumble into busy roads, or get into fights.

David Poley, chief executive of the Portman Group, which lobbies on behalf of the drink industry, said: "Drinks companies have no wish to see their products misused by binge drinking young adults. We therefore warmly welcome this government campaign, which complements the educational work already carried out by the industry."

A spokesman for Alcohol Concern said: "We think that this is a genuinely important initiative. Advertising can be effective if it is highly targeted in this way."

He warned, however, that advertising alone would not achieve the desired reductions in alcohol consumption, and he said that the drinks industry itself may have to make more concessions.

"We think, for example, that there are irresponsible pricing strategies. There are issues about the easy availability of alcohol. We'd like to see a more grounded and broad understanding of what makes young people drink," he said.

How the Department of Health promotes safer drinking 